\title{
Analisis Unit Cost Sectio Caesaria dengan Metode Activity Based Costing di Rumah Sakit Bhayangkara Yogyakarta
}

\section{Tsalisah Damayanti*}

*Penulis korespondensi: tsalisah.damayanti@yahoo.com

* Rumah Sakit Bhayangkara Yogyakarta, Daerah Istimewa Yogyakarta

\begin{tabular}{|c|c|}
\hline$I N D E X I N G$ & $A B S T R A C T$ \\
\hline Keywords: & This study aims to analyze the unit cost of sectio Caesaria by ABC method, second to analyze the \\
\hline Unit cost; & differences between the unit cost calculation of Sectio Caesaria by ABC method with applied cost. Unit \\
\hline Sectio Caesaria; & cost analysis was conducted at Sectio Caesaria procedure without comorbidities or complications. \\
\hline Activity Based Costing & $\begin{array}{l}\text { Data that used in the form of primary data interviews with specialists Obgyn and secondary data } \\
\text { financial data and hospitals profiles. The result of the calculation of unit cost of Sectio Caesaria service }\end{array}$ \\
\hline
\end{tabular}

\section{Kata kunci:}

Kos Unit;

Sectio Caesaria;

Pembebanan

Berdasarkan Aktivitas
Penelitian ini bertujuan untuk menganalisis unit cost Sectio Caesaria berbasis metode Activity Based Costing (ABC). tujuan selanjutnya adalah menganalisis perbedaan antara perhitungan unit cost Sectio Caesaria dengan metode ABC dengan klaim INA CBG's dan tarif RUMAH SAKIT Analisis Unit cost metode ABC dilakukan pada prosedur Sectio Caesaria tanpa penyulit. Data yang digunakan berupa data primer berupa wawancara dengan dokter spesialis Obgyn dan data sekunder berupa data keuangan dan profil rumah sakit. Hasil analisis unit cost pada pelayanan Sectio Caesaria melalui pendekatan ABC menunjukan bahwa hasil perhitungan unit cost melalui pendekatan ABC lebih rendah dibandingkan dengan tarif paket INA CBG's untuk semua kelas perawatan.

(C) 2017 JMMR. All rights reserved

$\overline{\text { Article history: Received } 5}$ Okt 2016; Revised 18 Nov 2016; Accepted 27 Des 2016

\section{PENDAHULUAN}

Rumah Sakit Bhayangkara sebagai penyelenggara layanan kesehatan di lingkungan Polri selain melayani pasien anggota dan keluarga juga melayani masyarakat umum. Rumah sakit Bhayangkara dituntut untuk memberikan pelayanan yang professional, bermutu lebih baik, dan harga yang relatif murah dan bermanfaat. Guna dapat memperhitungkan tariff yang sesuai, maka pihak rumah sakit maupun stakeholder perlu untuk menghitung secara riil berapa biaya pelayanan yang dibutuhkan dan bisa menjadi alat pertanggungjawaban dalam pembiayaan pelayanan kesehatan.

Dalam memutuskan besarnya tarif yang diberikan atau untuk menyusun besarnya anggaran suatu program pelayanan, maka perhitungan unit cost (unit cost) akan sangat membantu. Penentuan unit cost dalam analisis biaya diperlukan untuk mengetahui besarnya biaya yang benar-benar dibutuhkan untuk menghasilkan suatu produk baik berupa barang ataupun jasa, disamping tujuan lainnya seperti menilai efisiensi dalam anggaran.
Sampai saat ini, penentuan tarif di Rumah Sakit Bhayangkara Yogyakarta saat ini belum memperhitungkan unit cost dan belum bisa diketahui besarnya biaya yang dibutuhkan untuk suatu tindakan. Perhitungan tarif yang dilakukan di Rumah Sakit Bhayangkara Yogyakarta saat ini masih menggunakan pendekatan tradisional, yakni dengan penentuan yang didasarkan pada biaya secara keseluruhan, (total cost) yang dikeluarkan dalam suatu pelayanan yang diberikan, serta dengan membandingkan tarif tersebut dengan rumah sakit sekitar yang tipe kelasnya sama. Pendekatan semacam ini menjadikan berapa unit cost dari suatu pelayanan di Rumah Sakit Bhayangkara Yogyakarta tidak terhitung dengan baik. Berangkat dari hal tersebut, maka penentuan unit cost dengan pendekatan yang lebih modern dan memiliki akurasi perhitungan sangat penting untuk dilakukan.

Selain itu, analisis biaya melalui perhitungan unit cost dapat dipergunakan rumah sakit sebagai dasar pengukuran kinerja, penyusunan anggaran dan subsidi, alat negosiasi pembiayaan kepada stakeholder terkait dan dapat pula dijadikan acuan dalam mengusulkan tarif 
pelayanan rumah sakit yang baru dan terjangkau masyarakat. Dengan analisis ini dapat diketahui pusat biaya yang ada di rumah sakit, sehingga kepala rumah sakit akan lebih mudah mengidentifikasi pusat biaya mana yang mengalami defisit dan dengan mudah dapat dilakukan tindakan perbaikan.

Pada penelitian ini, kasus perhitungan unit cost dilakukan pada praktik Sectio Caesaria. Sectio Caesaria adalah suatu persalinan buatan, dimana janin dilahirkan melalui suatu insisi pada dinding perut dan dinding rahim dengan sayatan rahim dalam keadaan utuh bila ada indikasi medis. Rumah sakit Bhayangkara memiliki layanan unggulan selain kedokteran kepolisian juga untuk ibu dan anak. Pelayanan Sectio Caesar merupakan pelayanan paling banyak dilakukan di unit bedah sentral Rumah sakit Bhayangkara pada tahun 2015. Berdasarkan Gambar 1 dapat diketahui bahwa total pelayanan untuk bedah Caesar di Rumah sakit Bhayangkara dalah sebesar 309 kasus. Berdasarkan banyaknya kasus bedah Caesar inilah, maka peneliti memilih jenis pelayanan ini untuk dianalisis unit cost-nya.

Selain itu, kenapa pelayanan Caesar ini penting untuk dilakukan analisis biaya, hal itu berangkat dari semakin meningkatnya tuntutan masyarakat akan mutu pelayanan, maka fungsi pelayanan rumah sakit juga perlu ditingkatkan agar menjadi lebih efisien dan efektif. Di samping itu, Rumah sakit Bhayangkara juga melayani pasien Jaminan Kesehatan Nasional (JKN), yang klaimnya berdasarkan pada sistem pembayaran Indonesia Case Based Group (INA CBGs) atau pembiayaan dengan sistem paket. Berkaitan dengan hal tersebut maka diperlukan satu upaya penentuan tarif berdasarkan penghitungan unit cost menggunakan metode Activity Based Costing (ABC).

Berangkat dari berbagai paparan di atas, maka penelitian ini secara spesifik bertujuan untuk menganalisis unit cost Sectio Caesaria dengan metode ABC di Rumah Sakit Bhayangkara Yogyakarta, dan menganalisis perbedaan antara perhitungan unit cost Sectio Caesaria dengan metode ABC dengan tariff biaya yang diberlakukan saat ini di Rumah Sakit Bhayangkara Yogyakarta. Dari hasil penelitian studi kasus ini, diharapkan akan memberikan kontribusi praktis berupa konsep analisis biaya yang dapat diterapkan di Rumah Sakit Bhayangkara Yogyakarta pada umunnya, dan Rumah Sakit lain pada khususnya. Dalam konteks teoritis, hasil penelitian ini memberikan tambahan referensi yang memberikan penjelasan bagaimana konsep $\mathrm{ABC}$ dapat diterapkan dalam konteks organisasi sektor publk, khususnya Rumah Sakit.

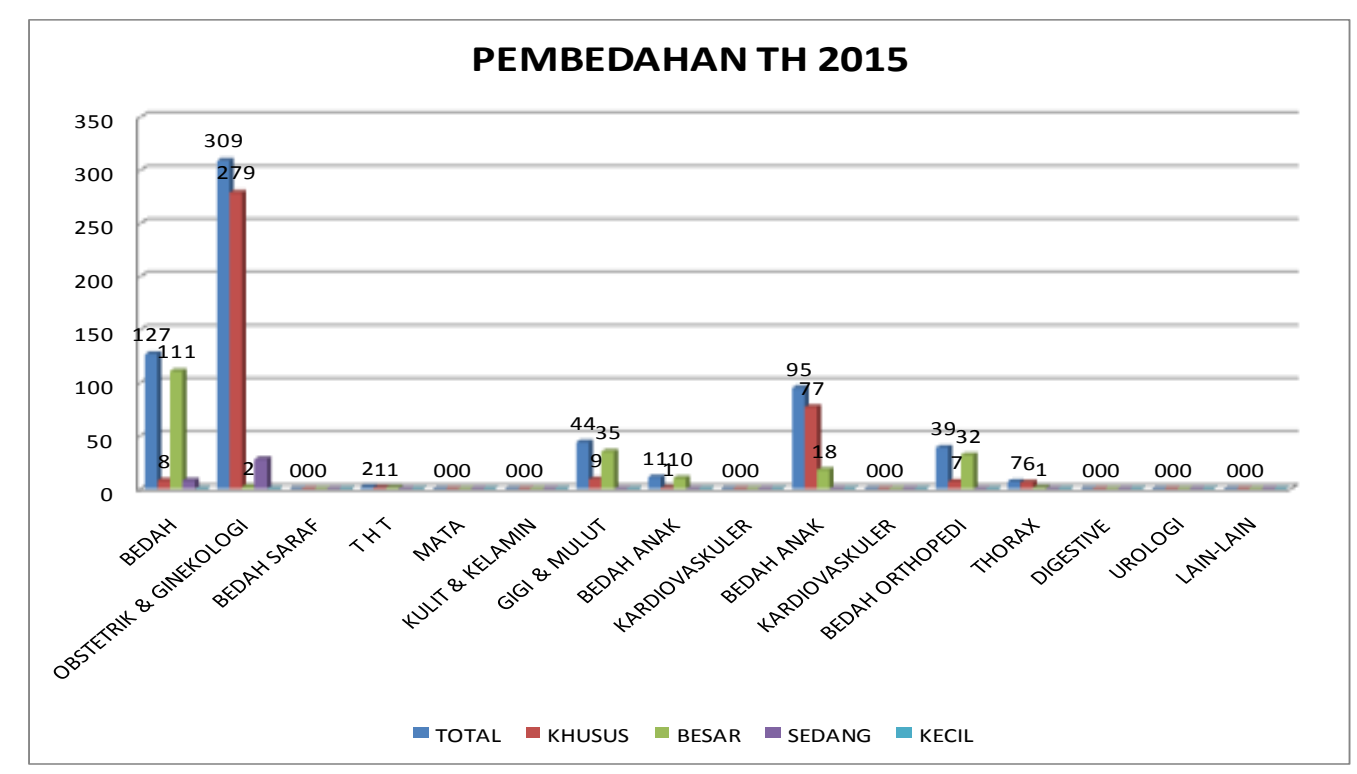

Gambar 1. Perbandingan Jumlah Pelayanan di Unit Bedah Sentral Rumah Sakit Bhayangkara tahun 2015 Sumber:Rumah Sakit Bhayangkara tahun 2016

METODE PENELITIAN 
Penelitian dilakukan pada prosedur Sectio Caesaria tanpa penyulit di Rumah Sakit Bhayangkara Yogyakarta. Data yang digunakan berupa data primer dan sekunder. Data primer dari enelitian ini yakni hasil dari wawancara dengan dokter spesialis Obgyn. Sedangkan data sekunder berupa data keuangan dari prosedur Sectio Caesaria serta profil rumah sakit. Teknik perolehan data dilakukan dengan wawancara tatap muka secara langsung, observasi atas laporan keuangan dan dokumentasi atas informasi-informasi keuangan yang diperlukan dalam proses alanisis unit cost. Analisis unit cost dengan menggunakan metode ABC. Analisis data dilakukan dengan pendekatan Activity Based Costing (ABC). ABC adalah penghitungan yang didasarkan pada biaya-biaya yang dikeluarkan secara nyata dalam rangka pelayanan kepada masyarakat. Metode ABC membebankan biaya aktivitas ke produk atau jasa berdasarkan konsumsi yang digunakan sehingga memberikan informasi tarif yang lebih akurat. ${ }^{1}$ Metode $\mathrm{ABC}$, dari perspektif manajerial, tidak hanya memberikan informasi biaya produk yang akurat namun juga menyediakan informasi kinerja dari aktivitas dan sumber daya serta dapat menelusuri biaya yang digunakan secara akurat ke obyek biaya selain produk, misalnya pelanggan dan saluran distribusi. Perhitungan biaya berdasarkan aktivitas merupakan pendekatan perhitungan biaya yang membebankan biaya sumber daya ke obyek biaya seperti produk, jasa, atau pelanggan berdasarkan aktivitas yang dilakukan untuk obyek biaya tersebut. ${ }^{2}$

Kelemahan metode ABC adalah: 1) Penerapan metode ini di rumah sakit belum sepenuhnya dipahami karena penerapannya baru dilakukan di beberapa dekade terakir. 2) Membuat beberapa manajer khawatir karena kinerja mereka dapat dinilai dari sini. 3) Waktu yang dibutuhkan untuk mengumpulkan semua data yang diperlukan relatif lebih lama dan membutuhkan biaya yang banyak. 4) Sangatlah sulit bagi pihak rumah sakit untuk dapat mengumpulkan semua data yang dibutuhkan. $\frac{3}{-}$ Menurut Roztocki tahapan pembebanan biaya pada aktivitas melibatkan 3 komponen yaitu sumberdaya, aktivitas dan produk layanan. Sumberdaya mengkonsumsi biaya yang dapat diklasifkasikan menjadi biaya tenaga kerja langsung (direct labour cost), biaya peralatan (equipment cost) dan biaya tidak langsung (indirect cost). -

\section{HASIL DAN PEMBAHASAN}

Berdasarkan observasi dan wawancara yang telah dilakukan dengan Dr. Spesialis Obsgyn, ditemukan informasi mengenai activity center yang ada dalam clinical pathway prosedur bedah caesar (lihat Tabel 2). Sedangkan dari hasil wawancara diperoleh informasi penggunaan sumberdaya pada tiap aktivitas disajikan dalam matrik centang hubungan aktivitas dengan biaya (lihat Tabel 2).

Tabel 3 menjelaskan proporsi pembebanan biaya berdasarkan cost driver pada masing-masing aktivitas hasil observasi dan wawancara. Tabel 4 menjelaskan nilai rupiah dari setiap aktivitas yang dilakukan dengan mengalikan proporsi aktivitas dengan total biaya langsung dan tidak langsung. Setelah diketahui konsumsi biaya per aktivitas, maka langkah selanjutnya adalah membebankan biaya aktivitas terhadap produk layanan.

Penentuan proporsi aktivitas dalam produk layanan adalah berdasarkan observasi dan wawancara terhadap Dr. Spesialis Obsgyn. Hasil wawancara terhadap Dr. Spesialis Obsgyn dapat diketahui bahwa secara umum tidak ada perbedaan proporsi aktivitas dalam layanan bedah caesar (sectio Caesaria) baik untuk kelas I, kelas II dan kelas III, kecuali untuk akomodasi.

Tabel 5 menjelaskan bahwa unit cost untuk Pelayanan Sectio Caesaria di RS Bhayangkara melali metode ABC adalah sebesar Rp 3.132,954 untuk Kelas I, sebesar Rp 3.028,756 untuk kelas II sebesar Rp 2.976,265 untuk kelas III. Jika dibandingkan dengan unit cost yang dihitung berdasarkan tindakan aktual, maka rata-rata besaran unit cost lebih rendah dibandingkan dengan klaim INA CBGs untuk prosedur sectio caesaria.

Ditinjau dari perbandingan dengan besaran klaim INA CBG's maka unit cost prosedur sectio caesaria di RS Bhayangkara Yogyakarta juga lebih baik untuk Kelas I, Kelas II dan Kelas III (Tabel 5). Analisis tersebut mengindikasikan bahwa besaran klaim untuk prosedur sectio saecaria sudah dapat menutup biaya pelayanan untuk prosedur tersebut. $\frac{5}{}$ Tarif jasa Pelayanan Sectio Caesaria RS Bhayangkara per kelas, yaitu untuk kelas I sebesar Rp 6.500.000, kelas II sebesar Rp 5.500.000, dan untuk kelas III sebesar Rp 4.750.000. 

Tabel 2. Matrix Centang Hubungan Konsumsi Biaya Penggunaan Sumberdaya Per Aktivitas Unit Pelayanan Sectio Caesaria

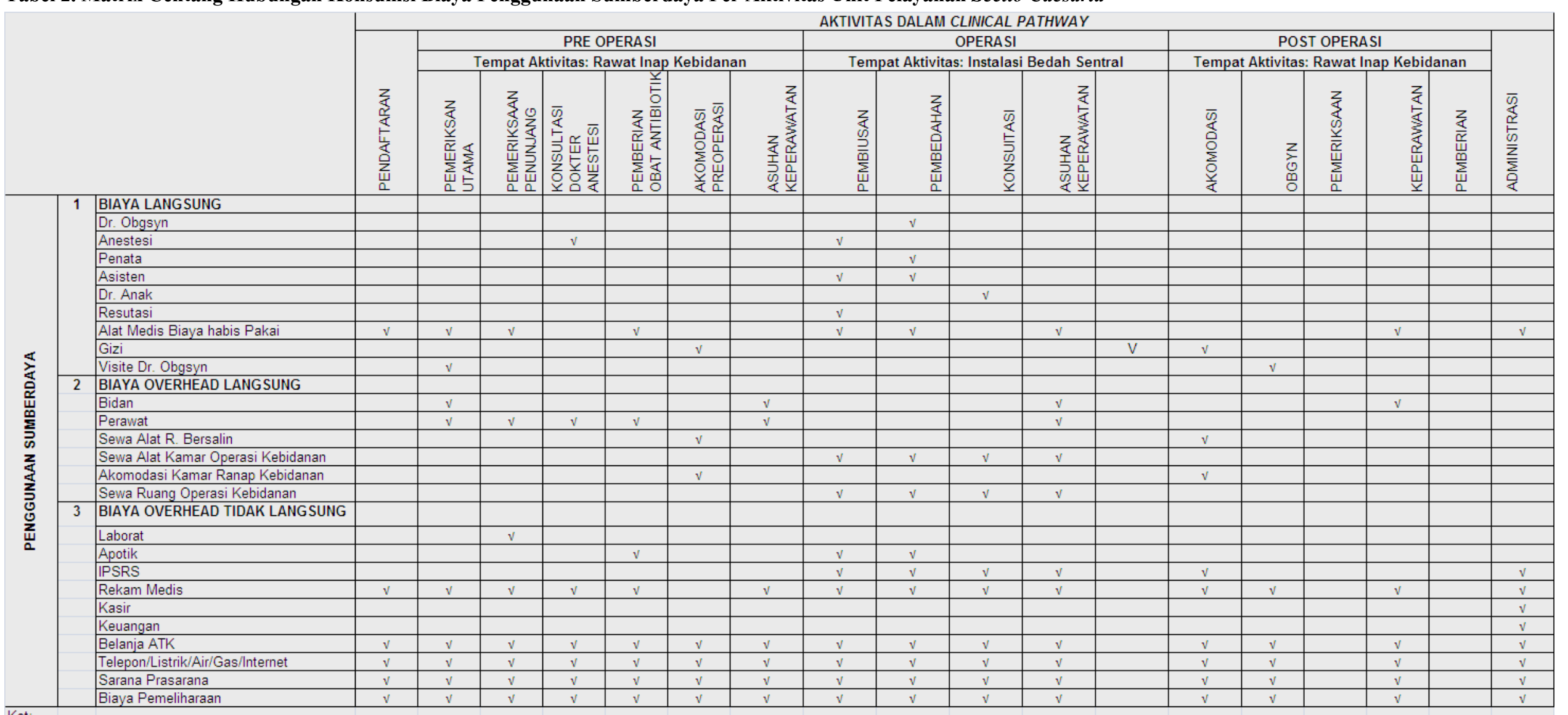

Ket:

$V=$ Ada Hubungan

Sumber: RS Bhayangkara Yogyakarta. telah diolah kembali 
Tabel 3. Proporsi Aktivitas berdasarkan Cost Driver ada Unit Pelayanan Sectio Caesaria di RS Bhayangkara Yogyakarta

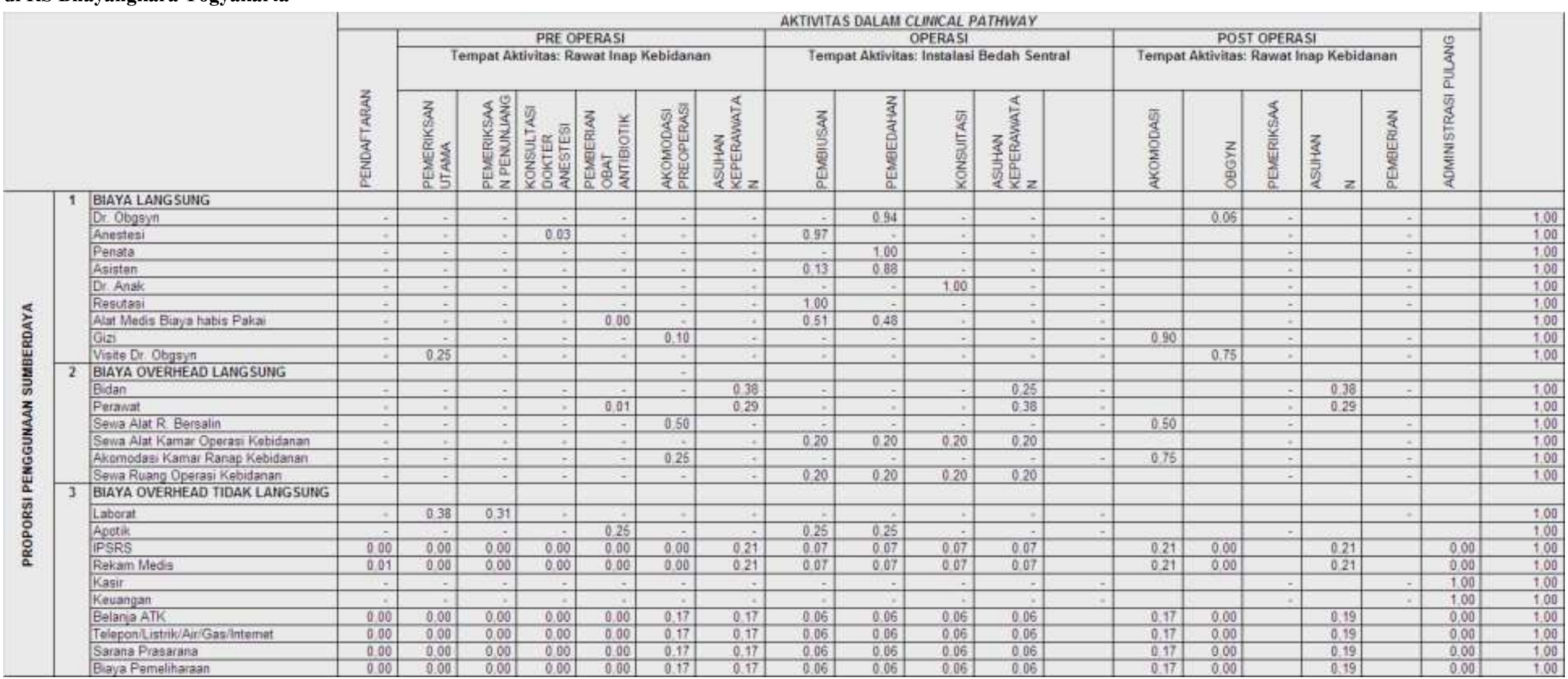

Sumber: diolah dari data RS Bhayangkara Yogyakarta (2015) 
Tabel 4. Matrix Proporsi EAD Hubungan Konsumsi Biaya Per Aktivitas Unit Pelayanan Sectio Caesaria RS Bhayangkara

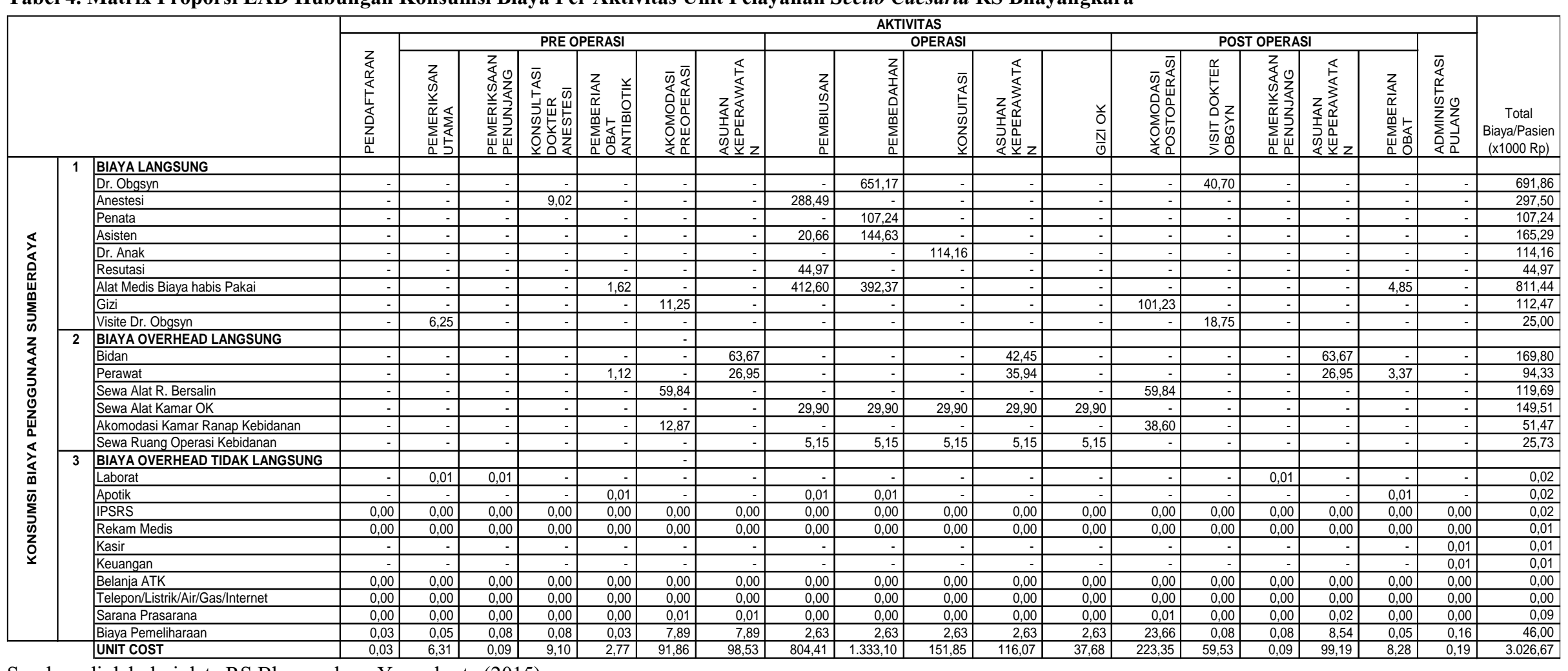

Sumber: diolah dari data RS Bhayangkara Yogyakarta (2015) 
Tabel 5. Perhitungan Biaya dalam Clinical Pathway Pelayanan Sectio Caesaria RS Bhayangkara Yogyakarta

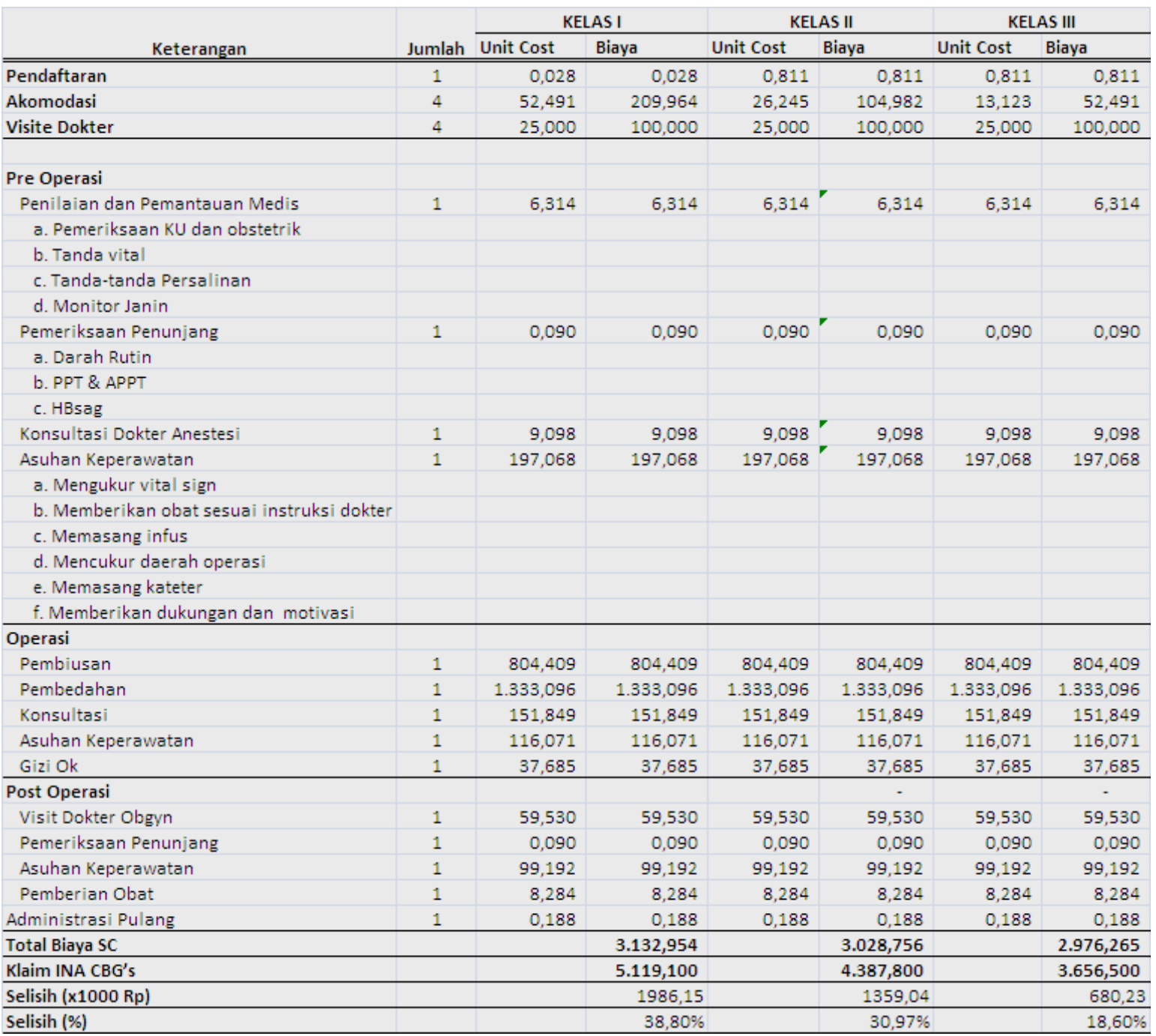

Sumber: diolah dari data RS Bhayangkara Yogyakarta (2015) dan PMK No. 59 Tahun 2014 Tentang Standar

Tarif JKN

Jika dibandingkan dengan tarif yang berlaku, maka tarif yang berlaku tersebut sudah berada diatas unit cost artinya rumah sakit tidak rugi. Perbedaan yang terjadi antara tarif prosedur Sectio Caesaria di RS Bhayangkara dengan metode Activity Based Costing adalah disebabkan karena rumah sakit harus memberlakukan system subsidi silang dalam penentuan tarifnya. Subsidi silang yaitu pemberian tarif yang lebih tinggi kepada masyarakat ekonomi kuat agar dapat ikut meringankan pembiayaan pelayanan rumah sakit bagi masyarakat ekonomi lemah. Kebijakan ini menyebabkan rumah sakit harus menarik biaya yang lebih rendah untuk kalangan kurang mampu (pasien kelas II dan kelas III) dan menarik biaya yang lebih tinggi dari unit cost untuk kalangan. Dari hasil penelitian diperoleh hasil bahwa jenis aktivitas yang paling tinggi konsumsi biaya (Tabel 5) adalah aktivitas operasi. Aktivitas operasi terutama dipicu oleh aktivitas pembedahan yaitu sebesar Rp 1.333,096 dan aktivitas Pembiusan sebesar Rp 804,409. Besarnya aktivitas terutama untuk membayar jasa medis langsung tindakan dokter spesialis Obgyn dan dokter anestesi.

Jumlah aktivitas yang ada di prosedur Sectio Caesaria, besaran harga pokok jasa tiap produk layanan juga dipengaruhi oleh volume aktivitas yang dikonsumsi oleh tiap produk jasa layanan. Selain jasa tindakan dokter pada saat operasi, aktivitas yang mengkonsumsi tinggi biaya adalah keperawatan Jam aktivitas perawat lebih besar dibanding tenaga lainnya. Pada prosedur sectio caesaria, perawat berperan dalam 
asuhan keperawatan (mengukur vital sign, memberikan obat sesuai instruksi dokter, memasang infus, mencukur daerah operasi, memasang kateter, memberikan dukungan dan motivasi, edukasi pasien pasca operasi (menyusui ASI ekslusif, perawatan bayi, perawatan lokas post operasi, parawatan post partum, mobilisasi bertahap, nutrisi ibu menyusui, KIE KB), pelaporan dan patient safety.

Aktivitas lain yang mempunyai porsi besar dalam mengonkumsi biaya adalah aktivitas akomodasi selama 4 hari perawatan yaitu sebesar Rp 209,964 untuk kelas I, sebesar Rp 104,982 untuk kelas II, dan sebesar Rp 52,491 untuk kelas III. Hal ini karena disebabkan investasi sarana tanah, bangunan paling besar dibanding fasilitas medis dan non medis yang lain. Biaya tersebut belum termasuk biaya pemeliharaan, jasa loundry dan investasi fasilitas. Aktivitas akomodasi lebih banyak mengkonsumsi biaya investasi tanah, bangunan, pemeliharaan dan sarana prasaraana. Pembebanan biaya tidak langsung akomodasi ke prosedur Sectio Caesaria kelas I, kelas II dan kelas III melalui penelusuran besaran aktivitas berdasarkan driver tracing yaitu berdasarkan luas ruang. Setelah informasi mengenai aktivitas di prosedur Sectio Caesaria diketahui maka akan dapat dipahami karakteristik setiap aktivitas di prosedur Sectio Caesaria. Perbaikan berkelanjutan dapat dilaksanakan secara efektif jika manajemen memiliki informasi aktivitas yang membentuk proses bisnis dan informasi penting yang berkaitan dengan aktivitas.

\section{SIMPULAN}

Hasil perhitungan unit cost pelayanan Sectio Caesaria (tanpa penyulit) melalui pendekatan Activity Based Costing didapat hasil: a) unit cost kelas I Rp 3.132,954, b) Kelas II Rp 3.028,756 dan c) unit cost Kelas III Rp 2.976,265. Hasil perhitungan unit cost melalui pendekatan Activity Based Costing didapat hasil unit cost yang lebih rendah dari unit cost yang belaku di RS Bhayangkara Yogyakarta. Hasil perhitungan unit cost pelayanan Sectio Caesaria melalui pendekatan Activity Based Costing juga lebih rendah dibandingkan rata-rata besaran klaim INA CBG's. Hasil perhitungan unit cost kelas I mempunyai selisih $38,80 \%$ untuk kelas I, 30,97\% untuk kelas II dan sebesar $18,60 \%$ untuk kelas III dibanding klaim INA CBG's.
Penelitian ini mempunyai beberapa keterbatasan sebagai berikut. Pertama, penelitian ini membatasi pada perhitungan unit cost pelayanan Sectio Caesaria tanpa penyakit penyerta/penyulit, sehingga belum dapat menjelaskan pengaruhnya terhadap unit cost. Penelitian unit cost pelayanan Sectio Caesaria dengan bauran kasus (casemix) diperlukan. Kedua, penelitian ini belum membedakan unit cost dengan tingkat pembedahan ringan ( 0 jam- 8 jam), sedang (8 jam -16 jam), atau berat (16 jam -24jam). Penelitian ini hanya membahas unit cost pelayanan Sectio Caesaria dengan lama pembedahan 0-8 jam.

Penerapan unit cost pada alur pelayanan yang dilalui pasien pada Pelayanan Sectio Caesaria dalam penelitian ini masih terbatas pada kasus Sectio Caesaria tanpa penyerta (penyulit), sehingga memerlukan pengembangan lebih lanjut terutama melalui bauran kasus pada tindakan klinis melalui kodifikasi dan standar alur pengobatan. Penelitian selanjutnya juga dapat membedakan unit cost dengan tingkat pembedahan ringan (0-8 jam), sedang (8-16jam), atau berat (16-24jam).

\section{DAFTAR PUSTAKA}

1. Aldogan M, Austill D, Kocakulah MC, 2014, 'The excellence of activity-based costing in cost calculation case study of a private hospital in Turkey,' Journal of Health Care Finance, June, 127.

2. Kuchta D \& Zabek S, 2011,'Activity-based costing for health care institutions,' 8th International Conference on Enterprise Systems, Accounting and Logictics Thassos Island Greece, 11-12 Juli: 300311

3. Yereli AN, 2009, Activity-based costing and its application in a Turkish University Hospital, AORN Journal, 3 (89), 573-591.

4. Roztocki, N. et al. 2004. A procedure for smoothing implementation of Activity Based Costing in small companies. Engineering Management Journal, 16(4), 19.

5. Mulyadi, 2007, Akuntansi Biaya Edisi Kelima, Aditya Media, Yogyakarta. 